\title{
Correction to: Assessing the Quality of Incident Investigations and its Effect on Safety Performance: a Study of the Ghanaian Mining Industry
}

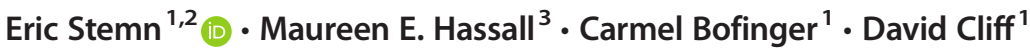

Published online: 22 May 2019

(C) Society for Mining, Metallurgy \& Exploration Inc. 2019

\section{Correction to: Mining, Metallurgy \& Exploration} https://doi.org/10.1007/s42461-019-0076-4

In the published article, Fig. 1 and Fig. 2 are the same. Figure 1 is incorrect and should be replaced with the figure shown below:
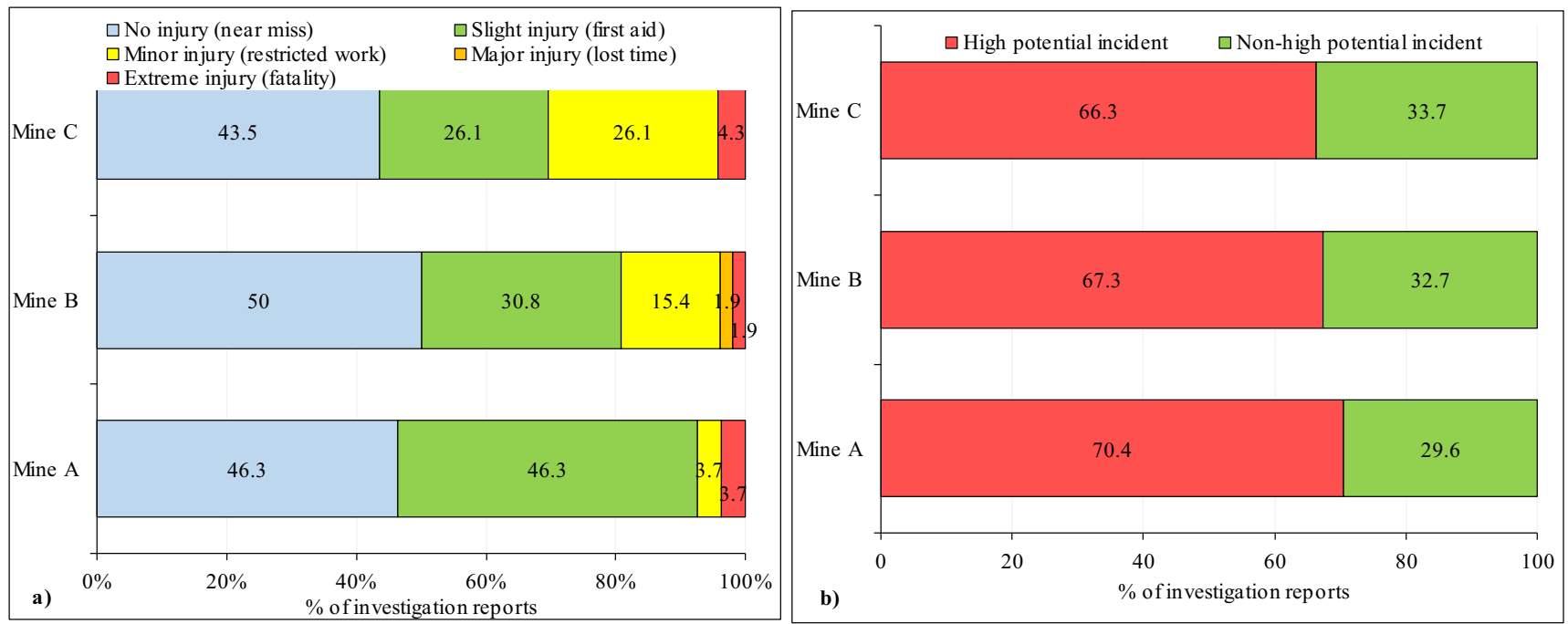

Fig. 1 Distribution of the $\mathbf{a}$ actual and $\mathbf{b}$ potential consequence of the incidents as described in the investigation reports

The online version of the original article can be found at https://doi.org/ 10.1007/s42461-019-0076-4

Eric Stemn

e.stemn@uq.edu.au; estemn@umat.edu.gh

1 Minerals Industry Safety and Health Centre, Sustainable Minerals Institute, The University of Queensland, Brisbane, QLD 4072, Australia

2 Environmental and Safety Engineering Department, University of Mines and Technology, P. O. Box 237, Tarkwa WT000, Ghana

3 The School of Chemical Engineering, The University of Queensland, Brisbane, QLD 4072, Australia 
In addition, two figures have been shown as Fig. 4. The top figure, which is the figure with the red line crossing, should not be part of the article, and must therefore be deleted. The correct figure for Fig. 4 is the bottom figure shown below:

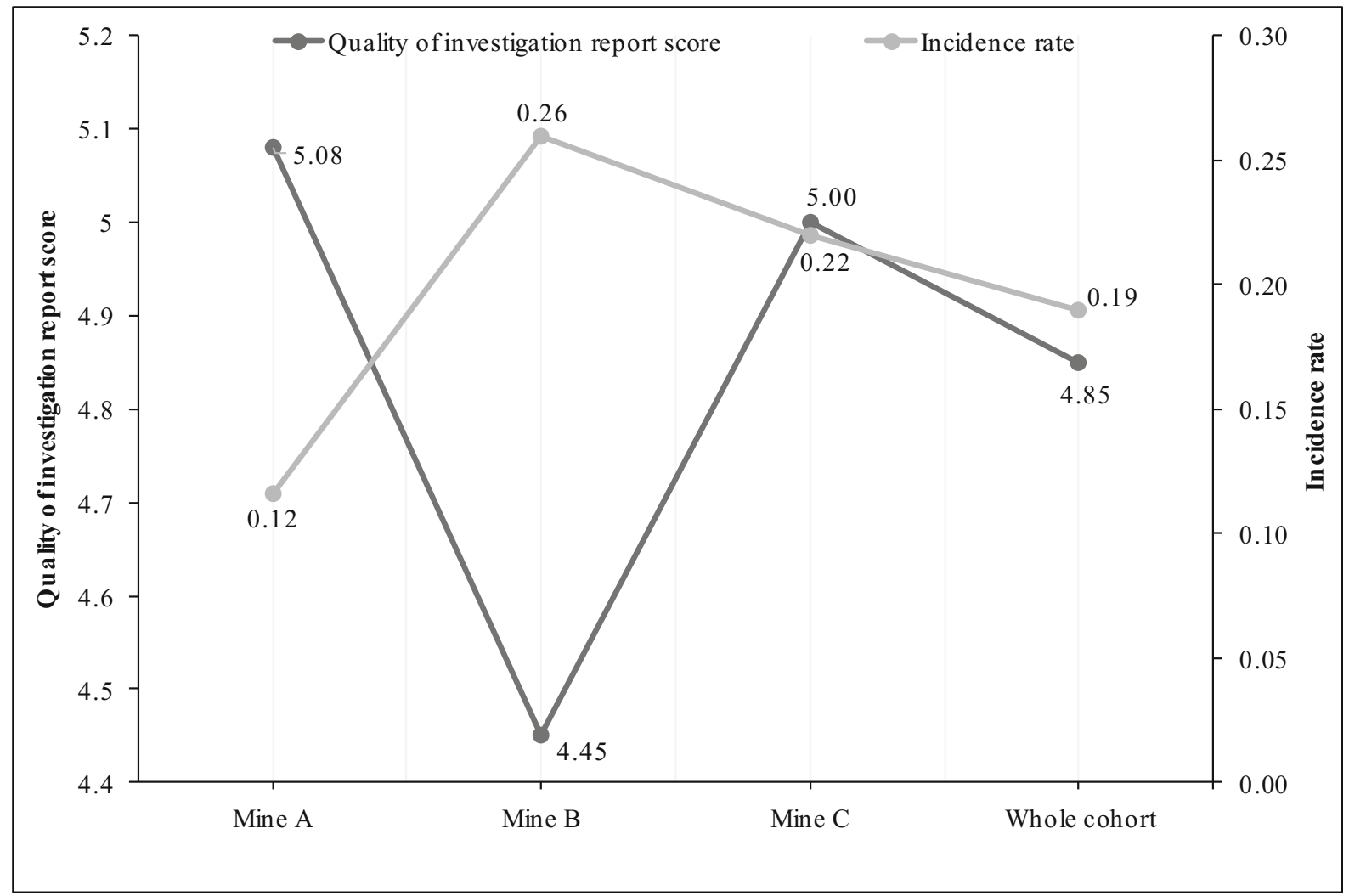

Fig. 4 Scatterplot of incidence rates and quality of investigation scores

Publisher's Note Springer Nature remains neutral with regard to jurisdictional claims in published maps and institutional affiliations. 